\title{
Editorial
}

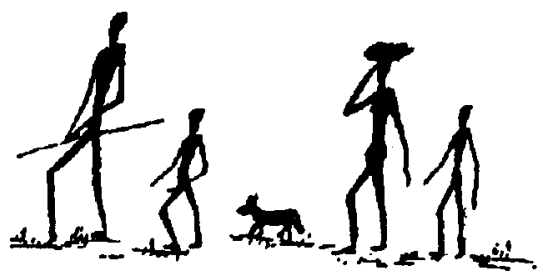

Once again the year is flying by and already the third edition of The Aboriginal Child at School is to hand. Four interesting and thought provoking articles have been selected, which we hope will assist you in your work with Aboriginal and Torres Strait Islander learners.

Jolly's paper examines the philosophy and practice of programs that aim to maintain, renew or revive Aboriginal languages in Australia. She reviews some basic issues that arise in planning language programs for which there are few, if any speakers, and considers some of the factors affecting the success of such programs.

Nakata looks at issues surrounding the use of English as the language of instruction for students in Torres Strait and raises many questions regarding language. He argues that Torres Strait Islanders need to regain some control of the intellectual enterprise that affects their schooling. He states that Torres Strait Islanders want to learn English, so that they can access Western knowledge systems and manage their own lifeways in the changing economies of the technological era - that Western education should be seen as a tool for understanding their position at the interface between their own and Western knowledge systems.

Christie's paper examines Aboriginal education and draws some interesting parallels between modern education practices in Aboriginal communities and 'modern secular missionaries', who he states' have a strong sense of mission to bring Aborigines from a state of darkness into the light' through the forum of 'white styles of administration' and the classroom. However, Aboriginal pedagogies are at last entering the classroom and he argues that teachers can no longer assume that community knowledges are of no relevance in the production of classroom knowledge - that the learning experience can be a two-way exchange of knowledge between Aboriginal and non-Aboriginal people in the ongoing education process.

Tripcony's paper was originally presented at a one-day conference for teachers, curriculum advisers, school support centre personnel and review officers. The paper brings to our attention major barriers to learning that are experienced by Aboriginal and Torres Strait Islander students, particularly those who are educated in urban and rural locations. She covers matters such as curriculum, identity and cultural backgrounds of urban Aboriginal and Torres Strait Islander students and language. She has also provided a reference list for further reading for teachers who wish to develop a more detailed knowledge of the issues she discusses in her paper.

In this issue we also have six Book Reviews that we hope you will find useful. We would like to draw your attention to the Guidelines for Contributors published for the first time in this issue and ask those of you who intend to contribute to the journal to keep them in mind when preparing your papers. 
Finally, as already noted in the Editorial of the first issue for 1995, we remind you that due to changes in Commonwealth funding, from 1996 all subscriptions to the journal will have to be financial to offset the considerable cost of production and distribution. We hope, however, that you will continue to support this important publication in 1996.

Kind regards,

¿awar Hin.

Dawn Muir
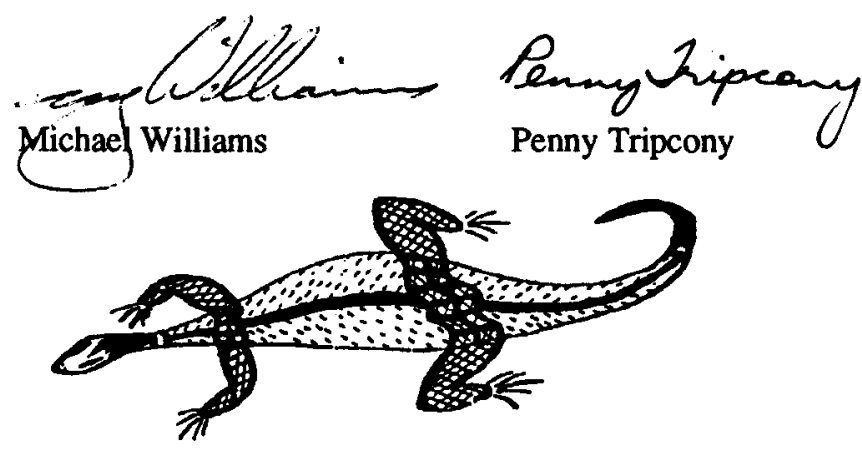

\section{Notice To Subscribers}

From the beginning of 1996 there will be a change in the way some subscribers receive The Aboriginal Child at School. Up to now, some schools have received one or two free copies of the journal depending on the number of Aboriginal and Torres Strait Islander students. Unfortunately, we are no longer able to do this, although for the remainder of 1995 some schools will continue to receive free copies of the journal.

To continue receiving the journal in 1996, however, all subscribers will need to take out a financial subscription. As always we will endeavour to keep subscription costs as low as possible.

Thank you for your continuing support. 